\title{
WILEY-VCH
}

DOI: 10.1002/((adma.201703608))

Article type: Communication

\section{Titanium fiber plates for bone tissue repair}

Takashi Takizawa, Noboru Nakayama, Hisao Haniu, Kaoru Aoki, Masanori Okamoto, Hiroki Nomura, Manabu Tanaka, Atsushi Sobajima, Kazushige Yoshida, Takayuki Kamanaka, Kumiko Ajima, Ayumu Oishi, Chika Kuroda, Haruka Ishida, Satomi Okano, Shinsuke Kobayashi, Hiroyuki Kato, and Naoto Saito*

Dr. T. Takizawa, Dr. M. Okamoto, Dr. H. Nomura, Dr. M. Tanaka, Dr. A. Sobajima, Dr. K. Yoshida, Dr. T. Kamanaka, Mr. A. Oishi, Dr. C. Kuroda, Dr. S.Kobayashi, Prof. H. Kato Department of Orthopaedic Surgery

Shinshu University School of Medicine

Asahi 3-1-1, Matsumoto 390-8621, Japan

Dr. N. Nakayama

Mecganicl Systems Engineering

Shinshu University Faculty of Engineering

Wakasato 4-17-1, Nagano 380-8553, Japan

Dr. H. Haniu, Dr. K. Ajima, Mr. H. Ishida, Ms. C. Kuroda, Mr. S Okano, Prof. N. Saito Institute for Biomedical Sciences

Interdisciplinary Cluster for Cutting Edge Research

Shinshu University

Matsumoto 390-8621, Japan

Dr. K. Aoki

Department of Applied Physical Therapy

Shinshu University School of Health Sciences

Asahi 3-1-1, Matsumoto 390-8621, Japan

E-mail: saitoko@shinshu-u.ac.jp

Keywords: Titanium fiber, plate, biomaterials, bone tissue repair, regenerative medicine 


\section{WILEY-VCH}

Having desirable features as a biomaterial, including light weight, excellent mechanical properties, and high biocompatibility, with high bone affinity, titanium has been widely used in clinical settings to fix and repair bone fractures in many fields, ${ }^{[1-3]}$ including orthopedics, face-head-neck surgery, dentistry, and oral surgery. ${ }^{[4-6]}$ However, because the Young's modulus of titanium is much higher than that of cortical bone, titanium plates can cause stress shielding, a phenomenon in which prolonged contact with bone reduces the physical load on bone leading to bone embrittlement. ${ }^{[7-9]}$ Therefore, conventional titanium plates require repeat surgery to remove them after the fracture has healed, ${ }^{[10]}$ and plate removal can pose risks resulting from bone formation around the plate, including difficulty with removing the plate, infections, and pain. ${ }^{[11-14]}$ Interlocking plates, which are implanted slightly above the bone surface, must likewise be removed because they can cause stress shielding. ${ }^{[10]}$ As shown in Table 1, the various titanium alloys have different Young's moduli. The currently available orthopaedic applications use Ti6A14V or beta alloys, which have lower Young's moduli, to prevent stress shielding. However, the Young's modulus of human cortical bone is reportedly 10-30 GPa, and thus considerably lower than the Young's moduli of titanium alloys, although it varies with age, health, sex, race, and other factors among human subjects. ${ }^{[4,15-17]}$ Consequently, stress shielding is unavoidable regardless of the type of titanium plate used, and it is therefore desirable to remove the plate from the bone after completion of bone repair. ${ }^{[7-9]}$

On the other hand, the number of patients needing repair of major bone defects during surgery for intractable fractures, bone tumor extirpation, spinal fixation, joint replacement, and the like has been increasing. ${ }^{[18-22]}$ Such patients often undergo autologous bone transplantation or allogeneic bone transplantation. ${ }^{[23-26]}$ However, both techniques are problematic: autologous bone transplantation, because of limits on the amount of bone that can be collected and the invasiveness of the bone harvesting technique; and allogeneic bone transplantation, because of its high cost, etc.. ${ }^{[23.24]}$ Therefore, there are expectations that the 


\section{WILEY-VCH}

recent advances in bone regenerative medicine will have practical use. As such, bone regenerative medicine requires a scaffold to serve as a basis for bone formation by retaining growth factors and cells; ${ }^{[27]}$ however, investigations of various materials have not yet find the most appropriate scaffold. ${ }^{[28-32]}$ Although conventional titanium plates are candidate scaffolds, bone forms on them and so they cannot be removed. ${ }^{[33-35]}$ Therefore, the conventional titanium plate must remain implanted after bone regeneration, which in turn poses problems including embrittlement of the regenerated bone and stratum bone due to stress shielding.

For these reasons, there has been great interest in the development of titanium plates that need not be removed because they do not produce stress shielding even after prolonged contact with bone, and act as a scaffold for fracture treatment and bone tissue regeneration. We expected that titanium fiber plates (which are easily prepared by simultaneously applying compression and shear stress to titanium fibers without heat treatment) would have these features. ${ }^{[37]}$ In the present study, titanium fiber plates having a Young's modulus similar to that of bone cortex (unlike conventional titanium plates) and a porosity suitable for scaffolds for growth factors and cells essential for bone regeneration were prepared by choosing the optimum titanium fiber materials, stress and load. Moreover, the utility of the plates for fracture repair and bone tissue regeneration was evaluated in vitro and in vivo.

A titanium fiber plate having a thickness of $0.2 \mathrm{~mm}$ was molded by simultaneously applying compression and shear stress to titanium fibers (Pure titanium, grade 1; diameter, 20 $\mu \mathrm{m}$; mean length, $500 \mu \mathrm{m}$; aspect ratio, 25) at normal room temperature (Figure 1a,b) (see Supporting Information) ${ }^{[36]}$ A circular plate having a diameter of $5 \mathrm{~mm}$ and a $5 \mathrm{~mm} \times 20 \mathrm{~mm}$ rectangular titanium fiber plate were prepared. A circular conventional titanium plate (2-2) (Pure titanium, grade 1) with the same diameter and thickness was used as a control. The Young's modulus of the titanium fiber plate was approximately $30 \mathrm{GPa}$, which is similar to that of cortical bone, i.e., 10-30 GPa. By comparison, the Young's modulus of the conventional titanium plate is approximately $110 \mathrm{GPa}$, which was approximately $4-10$ times 


\section{WILEY-VCH}

that of cortical bone. ${ }^{[36]}$ The titanium fiber plate had a porous structure with compressed titanium fibers, and its porosity was $30-40 \%$ and pore diameter was $60-80 \mu \mathrm{m}$, which were considered to be suitable for bone regeneration in past reports (see Supporting Information). ${ }^{[36]}$ The titanium fiber plate but not the corresponding conventional titanium plate could be manually reshaped into a curved three-dimensional structure.

Mouse pre-osteoblast MC3T3-E1 cells were seeded on a 5-mm disc of titanium fibers and 5-mm disc of conventional titanium at an initial cell density of $1.0 \times 10^{5}$ cells/plate. A 96well cell culture plate served as a control. Twenty-four hours later, the cell nuclei of the MC3T3-E1 cells were stained with Bisbenzimide H33342 Fluorochrome Trihydrochloride (H33342) and examined under a fluorescence microscope. Cell adhesion was good up to the periphery of both the titanium fiber plate and the conventional titanium plate (Figure 2a). After 2 and 5 days of culture, cell proliferation was measured using an Alamar blue assay. For the titanium fiber plate, conventional titanium plate, and cell culture plate, the extent of cell proliferation was statistically significantly greater on Day 5 than Day $2(\mathrm{p}<0.01)$; similar on Day 5 between the titanium fiber plate and the conventional titanium plate $(p=0.45)$; and statistically significantly greater on the titanium plates than on the cell culture plates $(p<0.01)$ $(n=3)$ (Figure 2b).

Bone marrow mesenchymal stem cells from the femur of a male Wistar rat at 10 weeks of age were cultured in a $10 \mathrm{~cm}$ dish. To promote osteoblast differentiation, recombinant human bone morphogenetic protein-2 (rhBMP-2) was added at a concentration of $100 \mathrm{ng} / \mathrm{mL}$ to the culture broth, and the cultivation was continued for 7 days. Differentiated osteoblasts were seeded onto the titanium fiber plate and the conventional titanium plate. On Day 1 after seeding, the cells were stained with H33342 to visualize the nuclei, stained with PhalloidinFITC to visualize actin fibers, and examined under a confocal laser microscope. On both plates, the differentiated osteoblasts had extensive cell processes. On the titanium fiber plate, 


\section{WILEY-VCH}

the osteoblasts adhered along the length of the titanium fibers (Figure 3a). Scanning electron microscopy showed that the titanium fibers were wound around the cell processes (Figure 3b).

Rat bone marrow mesenchymal cells, $1.0 \times 10^{5}$ cells, were stimulated to differentiate into osteoblasts in the presence of rhBMP-2 over 7 days, and the osteoblasts were seeded onto titanium fiber and conventional titanium plates. One day later, we collected the total RNA, synthesized cDNA, and then evaluated the expression level ratios for cell-adhesion-related genes using the RT2 Profiler PCR Array for adherens junctions (n=3) (Figure 3c). Of the 84 genes examined, 8 were expressed at statistically significantly higher levels in cells adherent to the titanium fiber plate vs the conventional titanium plate (Table 2). In particular, the expression level was 69.7 times higher for Dsp, 22.2 times higher for Dsc3, 8.7 times higher for Ppap2b, and 5.3 times higher for Dsc2. On the other hand, 9 genes were expressed at statistically significantly higher levels in cells adhering to the conventional titanium plate (Table 3). In particular, the expression level was 13.6 times higher for $\mathrm{Cdh}$ and 10.6 times higher for Dlg5. The mode of osteoblast adhesion differed at the gene level.

A $3 \times 3 \times 3 \mathrm{~mm}$ comminuted fracture was created at the center of the ulnar stem of 6 male Japan White rabbits at 6 weeks of age. A $5 \mathrm{~mm} \times 20 \mathrm{~mm}$ rectangular titanium fiber plate was pressure-bonded to the comminuted fracture in 3 rabbits, and fixed to the ulna using two stainless steel miniature screws (Figure 4a). The comminuted fracture in the remaining 3 rabbits (the control group) was left untreated (Figure 4b). Four weeks later, the extent of repair was evaluated using scout radiograms and micro-computed tomography $(\mu \mathrm{CT})$ images. No fragment dislocations occurred, and no implant breakage was found in the titanium fiber plate group. Bone repair with circumferential bone union was adequate in the implant group but inadequate (with some portions of the fracture found to lack bone continuity) in the control group (Figure 4c,d).

Disc-shaped titanium fiber plates and conventional titanium plates were coated with 5 $\mu \mathrm{g}$ of rhBMP-2, and each of four male ddY mice received a plate implant inserted into its 


\section{WILEY-VCH}

back muscle at 6 weeks of age. The mice were sacrificed at Week 3 after implantation, and areas of their back muscle were photographed using $\mu \mathrm{CT}$. The $\mu \mathrm{CT}$ images revealed distinct ectopic bone formation on both the titanium fiber plates and the conventional titanium plates (Figure 5a). The bone volume/tissue volume $(\mathrm{BV} / \mathrm{TV})\left(\mathrm{cm}^{3}\right)$ of each area of ectopic bone was calculated for each mouse. Since mean CT values were measured, total bone mass was calculated and compared. The volume of bone formed was $0.56 \pm 0.02 \mathrm{~cm}^{3}$ around the titanium fiber plate and $0.53 \pm 0.2 \mathrm{~cm}^{3}$ around the conventional titanium plate, showing no significant difference $(\mathrm{p}=0.83)$. The total bone mass was $347.4 \pm 59.5 \mathrm{mg}$ for the titanium fiber plate group and $364.5 \pm 145.4 \mathrm{mg}$ for the conventional titanium plate group, showing no significant difference between the two groups $(\mathrm{p}=0.73)$ (Figure 5b).

After $\mu \mathrm{CT}$ photographing, the titanium fiber plates and the conventional titanium plates were resected, along with soft tissue around each of them, and prepared as tissue specimens for examination under a light microscope. Ectopic bone formation was found around both plates, and bone tissue formation was also observed in the interspaces of the titanium fiber plate (Figure 5c).

Bone marrow mesenchymal stem cells from the femur of male Wistar rats at 10 weeks of age were cultured in rhBMP-2-containing $\alpha$-MEM medium for 7 days, and subjected to an alkaline phosphatase (ALP) assay. The cells cultured in rhBMP-2-containing medium had significantly more ALP activity compared with cells cultured in rhBMP-2-free medium $(\mathrm{BMP}+; 1.825 \pm 0.415 \mathrm{~mol} / \mathrm{g}$ vs BMP-; $1.052 \pm 0.067 \mathrm{~mol} / \mathrm{g}, \mathrm{p}=0.001)$, and were subsequently shown to have differentiated into osteoblasts (Figure 6a). Cells seeded onto titanium fiber plates or conventional titanium plates at $1.0 \times 10^{5}$ cells/plate were cultured overnight to allow them to adhere. One $5 \mathrm{~mm}$ wide defect was created in the center of the skull of each male Wistar rat at 10 weeks of age, and the cell-coated titanium fiber plate or cell-coated conventional titanium plate was placed in the defect $(n=5)$. Eight weeks later, the rats were sacrificed; histological specimens of the skull were prepared, and the bone regeneration 


\section{WILEY-VCH}

capacity was evaluated. In both groups, a trabecular structure with bone marrow tissue was observed at the interface of the implant with the skull bone defect. Bone tissue had formed around the titanium fiber plate, and bone regeneration was good. However, bone tissue covered only part of the conventional titanium plate, and regeneration in the defect was inadequate (Figure 6b). The percentage contact between the plate and the bone tissue (defined as the length of regenerated bone tissue covering the plate/the full length of the plate) was approximately 2.8 times, statistically significantly higher, for the titanium fiber plate than for the conventional titanium plate $(72.0 \pm 27.1 \%$ vs $25.4 \pm 17.7 \%, \mathrm{p}=0.012)$ (Figure 6c).

Our titanium fiber plates, unlike conventional titanium plates, are prepared by compressing titanium fibers at normal room temperature into plates without changing the fiber shape. This simple process of ours produced titanium fiber plates having a Young's modulus similar to that of bone cortex and less than $30 \%$ of that of conventional titanium plates of the same thickness. Therefore, the titanium fiber plate does not cause bone embrittlement even after close contact with bone for prolonged periods, thus compensating for the major drawback of conventional titanium plates, and finding application in a range of fixation and bone tissue repair uses at various sites of the body. Furthermore, taking advantage of titanium fibers as a base material, we were able to use the titanium fiber plate as a scaffold for bone regeneration. Specifically, since the shape of titanium fibers is preserved without special treatment, a unique porous environment is created throughout the plate. ${ }^{[36]}$

Data on the Young's modulus, as the most representative mechanical property of titanium fiber plates involved in stress shielding, are presented. Although stress shielding is influenced by other mechanical properties, the Young's modulus has been used in many previous studies on bone fixation materials and stress shielding. ${ }^{[37-38]}$ While the threshold of the Young's modulus for non-occurrence of stress shielding remains disputable, a recent study reported that stress shielding decreases with decreasing Young's modulus. ${ }^{[9]}$ In addition, titanium fiber assemblies undergo different levels of stress depending on the orientation of the 


\section{WILEY-VCH}

fibers. However, as evident from Figure 1c, the Young's modulus did not change depending on the direction of pulling because the titanium fibers in the titanium fiber plates were aligned randomly.

With regard to porous bodies, there are generally diverse opinions on the best pore diameter for the promotion of bone ingrowth. As a previous study reported that neoplastic bone ingrowth into pores can occur with a pore diameter of $\leq 50 \mu \mathrm{m}$, the pore diameter of our titanium fiber plates was set at $60-80 \mu \mathrm{m}$. However, it should be noted that this pore diameter can be adjusted as appropriate at the time of molding. Therefore, it is possible to prepare a titanium fiber plate with the best pore diameter suitable for the anatomical site and manner of use. ${ }^{[39]}$ Meanwhile, because titanium fiber plates have a fiber-stacked structure, it remains unknown whether their interconnections are as effective as those in ordinary porous bodies, and thus further investigations are needed. Although titanium meshes, a form of porous titanium, are already used in clinical applications, they are nothing more than ordinary titanium plates with artificial pores, being completely different from titanium fiber plates in terms of manufacturing method, structure, and mechanical properties. ${ }^{[34,40-41]}$ Although such titanium meshes have lower Young's moduli than those of ordinary titanium plates, their Young's moduli cannot be close to the Young's modulus of human cortical bone, unlike the case for titanium fiber plates. ${ }^{[42-44]}$ As the present study was the first to examine the capacity of titanium fiber plates for bone repair, we used conventional titanium plates as controls because they can be defined by material and size only, unlike titanium meshes that are highly variable in porosity and pore size. Further investigations are required to compare titanium fiber plates and titanium meshes, including their genetic expression profiles.

In vitro testing showed that the extent of osteoblast adhesiveness and proliferation was nearly the same on titanium fiber and conventional titanium plates. However, morphological examination showed that osteoblasts adhered to the titanium fiber plate as the titanium fibers were wound around the cell processes. After culturing osteoblasts differentiated from bone 


\section{WILEY-VCH}

marrow mesenchymal cells for 1 day, we identified 8 cell adhesion genes with higher expression levels in cells on the titanium fiber plate than in cells on the conventional titanium plate and 9 cell adhesion genes with higher expression levels in cells on the conventional titanium plate than in cells on the titanium fiber plate. As stated above, expression levels for cell-adhesion related genes differed between cells on fiber plates and cells on conventional plates, suggesting a difference in cell adhesion mode at the gene level between these two plates. From the viewpoint of tissue engineering, an ideal bone regeneration scaffold should be a porous material having a pore structure that allows cell adherence. ${ }^{[45-47]}$ Our present results seem to show that the unique three-dimensional structure of the titanium fiber plate confers osteoblast adhesion properties that are different from those of the conventional titanium plate with simple planar structure.

In the in vivo study in rabbits, we showed that comminuted ulnar fractures involving small bone fragments could be repaired, while keeping the small bone fragments immobilized, by placing the titanium fiber plate in close contact with the fractured bone. The most common clinical application of titanium plates is treatment of bone fractures. ${ }^{[48]}$ Traditionally, a titanium plate surface was fixed in close contact with bone; at present, however, use of a locking plate system to fix the titanium plate above and away from the bone surface is the preferred method. ${ }^{[49]}$ The reasons include the prevention of interference with bone repair capacity of periosteum on bone surfaces and maintenance of adequate blood flow; however, the problem with stress shielding (bone embrittlement following bone repair) remains unresolved. ${ }^{[49]}$ In addition, comminuted fractures hinder small bone fragment retention; it is more advantageous to bring the surface of the plate into close contact with the fractured portion of the bone. ${ }^{[48,50-52]}$ Since it has a Young's modulus similar to that of cortical bone, the titanium fiber plate used in the present study does not cause stress shielding and can remain implanted after the fracture has healed. In addition, since the plate is easily manually deformable and shaped optimally during surgery, it can be used for preventing bone fragment 


\section{WILEY-VCH}

loss from comminuted fractures containing such fragments. In addition, since it is thin and easily deformable, the titanium fiber plate is suitable for fractures at sites where the space around the plate is limited or absent, e.g., ulnar and phalangeal fractures. The titanium fiber plates also allow holes to be drilled for insertion of small screws at given sites during surgery. Titanium fiber plates are highly useful in clinical management of bone fractures as they do not produce stress shielding and are readily malleable.

We also showed that the extent of bone formation was equivalent on titanium fiber and conventional titanium plates in an ectopic bone formation test using rhBMP-2-coated plates, and was better on titanium fiber plates in a skull bone repair test using plates coated with osteoblasts differentiated from bone marrow mesenchymal stem cells. This difference demonstrates that the pores in the titanium fiber plate used in the present study improve cell function, although their ability to retain and slowly release growth factors is not high. Because of the porous structure of the titanium fiber plate, it can excellently retain cells and thereby serve as a scaffold for bone tissue to regrow and merge with bone to form neoplastic bone. This hybrid material consisting of the titanium fiber plate and cells could readily be placed at regeneration sites, and remain there for a prolonged period because its Young's modulus is similar to that of bone. As such, this new material is expected to facilitate bone regeneration.

Titanium fiber plates are not so tough that they can endure high mechanical loads. In addition, if a titanium fiber plate remains attached to a bone bearing loads for a long time, its titanium fibers can rub against one another to produce wear dust. ${ }^{[53]}$

However, even in bones bearing major loads, titanium fiber plates can be useful for immobilizing small bone fragments in comminuted fractures when used in combination with another fixation device (e.g., external fixation device). Furthermore, even when used alone in a bone bearing major loads, a titanium fiber plate can mainly allow the bone to endure the loads after completion of bone formation by starting the use without loading and gradually increasing the load level to keep pace with the progression of bone union. At this stage, bone 


\section{WILEY-VCH}

tissue has entered the spaces among the titanium fibers, providing unity between the titanium fiber plate and the stratum bone. Therefore, we expect that no wear dust will be produced. Hence, titanium fiber plates can be used in load-bearing sites with use of an appropriate method, and can exhibit their desired effects in clinical settings for many bone diseases.

In the present study, the first priority was given to the preparation of titanium fiber plates with a Young's modulus similar to that of cortical bone and a porosity favorable to bone ingrowth. Notably, plate thickness, surface properties, porosity, Young's modulus, strength, and other properties can be controlled by adjusting material titanium fiber thickness, fiber length, and the level of compression and shear stress. ${ }^{[36]}$ Thus, appropriate titanium fiber plates with still lower Young's modulus, greater malleability, and greater porosity for growth factor retention and sustained-release can be customized to the site's bone fixation, bone regeneration, shape, and use requirements. Titanium fiber plates can be used in a wide variety of fracture treatments including bone regeneration. Furthermore, metal fibers must be solidified and molded by sintering that usually takes at least several hours, while titanium fiber plates can be prepared in several minutes, because it is simply necessary to apply compression and shear stress simultaneously to the titanium fibers at normal room temperature. In addition, their price is comparable to that of conventional titanium plates, making them easy to commercialize. Since the base material is titanium, and the diameter of the fibers is on the order of $\mu \mathrm{m},{ }^{[39,54-56]}$ the biosafety of these plates seems to be high. In the present study, both the titanium fiber plates and conventional titanium plates were prepared with pure titanium to avoid any toxic impacts of metals released from titanium alloys, e.g., $\mathrm{Nb}$ and A1. ${ }^{[17]}$ However, titanium alloys, which have traditionally been used in the construction of medical prostheses, can be used to prepare the plates in the same manner. ${ }^{[36]}$ It is hoped that bone repair technology with titanium fiber plates will be used clinically to treat various diseases. 


\section{WILEY-VCH}

\section{Experimental Section}

Titanium fiber plates and conventional titanium plates: The titanium fiber plates were prepared from titanium fibers having a mean diameter of $20 \mu \mathrm{m}$, a mean length of $500 \mu \mathrm{m}$, and a purity of $99.52 \%$ (ASTM Grade 1) (Figure S1, Supporting Information). The material was molded into a plate under a compression stress of $1000 \mathrm{MPa}$ and a shearing load of 400 $\mathrm{kN}$ at room temperature and then sintered at $300 \mathrm{~K}$ (Figure S2, Supporting Information). This titanium fiber plate had a thickness of $0.2 \mathrm{~mm}$, an isotropic uniform porous structure with a Young's modulus of approximately $30 \mathrm{GPa}$, a porosity of $30-40 \%$, and a pore diameter of 60 $80 \mu \mathrm{m}$. Detailed methods for preparing the titanium fiber plate and measuring porosity are described in the Supporting Information. ${ }^{[36]}$ Adisc-shaped plate having a diameter of $5 \mathrm{~mm}$ was cut from the titanium fiber plate using a piercing punch (9W1203, Lion, Tokyo, Japan). A $5 \mathrm{~mm} \times 20 \mathrm{~mm}$ rectangular plate was also prepared using scissors. The plates were sterilized by immersion in $99.5 \%$ ethanol for 1 hour, and dried in an incubator at $37^{\circ} \mathrm{C}$ for 24 hours. The conventional titanium plate with a diameter of $5 \mathrm{~mm}$ and a thickness of $0.2 \mathrm{~mm}$ was prepared from tabular titanium (Nikko Techno, Tokyo, Japan). This plate was sterilized in the same manner as titanium fiber plates.

Evaluation of adhesiveness and proliferation capacity of MC3T3-E1 cells on the titanium fiber plate: MC3T3-E1 cells (mouse preosteoblasts) (Riken, Tsukuba, Japan) at 1.0 $\times 10^{5}$ cells $/ \mathrm{mL}$ were cultured in $\alpha$-MEM (Nacalai Tesque, Kyoto, Japan) supplemented with $10 \%$ fetal bovine serum (FBS) (Biowest, Nuaillé, France) at $37^{\circ} \mathrm{C}$ in the presence of $5 \% \mathrm{CO}_{2}$, and passaged twice a week.

The disc-shaped titanium fiber plate and the conventional titanium plate $(n=3$ for each plate) were placed at the bottom of a 96-well cell culture plate, and cell adhesiveness was evaluated. MC3T3-E1 cells were seeded at an initial concentration of $1.0 \times 10^{5}$ cells/plate in $100 \mu \mathrm{L}$ of medium/well. Each titanium plate was removed 24 hours after cell seeding, then 


\section{WILEY-VCH}

stained with a fluorescent dye $(0.5 \mu \mathrm{g} / \mathrm{mL}$ Bisbenzimide H33342 [H33342, Nacalai Tesque, Kyoto, Japan]) to visualize cell nuclei, and evaluated for cell adhesiveness using a fluorescence microscope (IX71, Olympus, Tokyo, Japan). Two and five days after cell seeding, fluorescence intensity was measured at excitation/emission=550/600 nm ( $\mathrm{n}=3)$. The medium was aspirated from each well, and 10\% Alamar blue (Thermo Scientific, Lenexa, KS, USA) in $100 \mu \mathrm{L} \alpha$-MEM medium/well was added. One hour later, the fluorescence intensity of cells adhering to the culture plate surface, cells adhering to the titanium fiber plate, and cells adhering to the conventional titanium plate were measured using a fluorescence microplate reader (POWERSCAN 4, DS Pharma Biomedical, Osaka, Japan).

Evaluation of cell adhesion to a titanium fiber plate following the induction of rat bone marrow mesenchymal cells differentiation into osteoblasts: Cells induced to differentiate into osteoblasts using the above-described method were seeded in $\alpha$-MEM medium supplemented with $100 \mu \mathrm{L}$ of $10 \%$ FBS at an initial concentration of $1.0 \times 10^{5}$ cells/plate, onto the discshaped titanium fiber plate and the conventional titanium plate. After overnight cultivation, cell morphology and adhesion to the titanium fiber plate and the conventional titanium plate were evaluated. Cells were fixed using 4\% paraformaldehyde phosphate buffer solution (Nacalai Tesque, Kyoto, Japan), treated with $0.1 \%$ Triton $\mathrm{X}$ to render cells permeable, stained with $0.5 \mu \mathrm{g} / \mathrm{mL}$ H33342 to view cell nuclei, and stained with $0.2 \mu \mathrm{g} / \mathrm{mL}$ phalloidin-FITC to view intracellular actin (Sigma-Aldrich, St. Louis, MO, USA) under a confocal laser scanning microscope (LSM 5 EXCITER, Zeiss, Oberkochen, Germany). After being fixed in 2.5\% glutaraldehyde (TAAB, UK) for 24 hours, transferred onto a sample stage, and examined using a scanning electron microscope (JSM-7600F, JEOL, Tokyo, Japan).

Gene expression analysis of rat bone marrow mesenchymal cells following induction of differentiation of rat bone marrow mesenchymal cells adhering to the titanium fiber plate: Osteoblasts that had differentiated from rat bone marrow mesenchymal stem cells $\left(1.0 \times 10^{5}\right.$ cells/scaffold/well) using the above-described method, were seeded onto titanium fiber plates 


\section{WILEY-VCH}

and conventional titanium plates, and cultured in100 $\mu \mathrm{L} /$ well of $\alpha$-MEM medium supplemented with 10\% FBS for 1 day, after which total RNA was collected. Cells adherent to the conventional titanium plates and titanium fiber plates from twenty 96 -well cell culture plates were lysed with TRIzol ${ }^{\circledR}$ Reagent (Life Technologies, Carlsbad, CA, USA). The pooled lysates from fiber plates and conventional plates were treated separately to extract total RNA using the Purelink ${ }^{\mathrm{TM}}$ RNA Mini kit (Life Technologies, Carlsbad, CA, USA). The total RNA was quantified using the NanoDrop ${ }^{\text {TM }} 2000$ spectrophotometer (Thermo Scientific, Waltham, MA, USA), and cDNA was synthesized using the ReverTraAce ${ }^{\circledR} \mathrm{qPCR}$ RT Master Mix with gDNA Remover (Toyobo, Osaka, Japan). Quantitative real time PCR of the RT ${ }^{2}$ Profiler PCR Array for rat adherens junctions (Qiagen, Hilden, Germany)was performed with $\mathrm{RT}^{2}$ SYBR Green ROX qPCR Mastermix (Qiagen, Hilden, Germany) on the StepOne Plus real time PCR system (Life Technologies, Carlsbad, CA, USA), and the expression level ratios for celladhesion-related genes were evaluated. The data were calculated from the means for $n=3$ samples.

Method of stimulating and evaluating ulnar comminuted fracture repair in rabbits: Male Japan White rabbits (6 weeks of age; SLC, Shizuoka, Japan) were anesthetized by intravenously administering pentobarbital (Somnopentyl, Kyoritsu Seiyaku, Tokyo, Japan) at $40 \mathrm{mg} / \mathrm{kg}$. A $3 \times 3 \times 3 \mathrm{~mm}$ comminuted fracture containing small bone fragments was created at the center of the rabbit ulnar stem using a bone saw. A $5 \mathrm{~mm} \times 20 \mathrm{~mm}$ rectangular titanium fiber plate was placed on the surface of the ulna along the longitudinal axis, centered over the fracture site, and drilled at each end to permit fixation with stainless steel miniature screws 1 $\mathrm{mm}$ in diameter and $8 \mathrm{~mm}$ in length (Tomimori, Shizuoka, Japan). In control animals, a comminuted fracture of the same size was created but left untreated. After fracture creation, the titanium fiber plate group ( $n=3)$ and the control group $(n=3)$ were assessed for the absence of bone fragment dislocations at all comminuted fracture sites using fluoroscopy. At Week 4 postoperatively, bone healing in the two groups was evaluated using scout radiography 


\section{WILEY-VCH}

(BV25; Philips, Amsterdam, Netherlands) and micro-computed tomography $(\mu \mathrm{CT})\left(\mathrm{R} \_\mathrm{mCT}\right.$, Rigaku, Tokyo, Japan). In the $\mu \mathrm{CT}$, data were corrected for metal halation effects by adjusting voltage and amperage. Images were taken at a tube voltage of $80.0 \mathrm{kV}$ and a tube amperage of $60.0 \mu \mathrm{A}$ for 17 seconds. Images were reconstituted using the $\mathrm{i}$-View software program ( $\mathrm{J}$. Morita MFG., Kyoto, Japan), and image conditions were made uniform by constantly keeping a window level of 50,000 and a window width of 10,000 using the ATLAS Tif converter software program (VERSION 2.03.2009, Rigaku, Tokyo, Japan), and re-adjusting for $1 \mathrm{~mm}$ slices.

Evaluation of rhBMP-2-induced formation of ectopic bone in the back muscle of mice: Disc-shaped titanium fiber plates and conventional titanium plates were uniformly coated with rhBMP-2 $(5 \mu \mathrm{g}$ dissolved in $5 \mu \mathrm{L}$ of pure water $)$ and dried at $37^{\circ} \mathrm{C}$ overnight. After anesthetizing male ddY mice (6 weeks of age; SLC, Shizuoka, Japan) with isoflurane (Forane; Abbott, Chicago, IL, USA), their back skins and fascia were incised. Each of the titanium fiber plate and the conventional titanium plate, having rhBMP-2 adhering thereto, was aseptically implanted in the back muscle in 4 animals, after which the skin was sutured. At week 3 postoperatively, the mice were euthanized with isoflurane, and photographed using $\mu \mathrm{CT}$ under uniform imaging conditions as described above. The images obtained were analyzed using the ImageJ software program $\left(\mathrm{NIH}\right.$, Bethesda, MD, USA) ${ }^{[57]}$. Slices containing ectopic bone were selected, and a region of interest (ROI) in the ectopic bone region was drawn in each slice. Thresholds were set for the metal and bone tissue, and for the bone tissue and muscle tissue to make bone tissue conditions uniform $(0.1 \%$ and $0.4 \%$, respectively, of the max gray value). The CT values and areas of all ROIs were measured, and the mean $\mathrm{CT}$ value and bone volume/tissue volume $(\mathrm{BV} / \mathrm{TV})\left(\mathrm{cm}^{3}\right)$ were calculated for each mouse. With a correction using the UHA model bone mineral quantitation phantom (hydroxyapatite concentrations $0,100,200,300$, and $400 \mathrm{mg} / \mathrm{cm}^{3}$ ) (Kyoto Kagaku, Kyoto, Japan), mean CT values were converted to BMD $\left(\mathrm{g} / \mathrm{cm}^{3}\right)$. Total bone mass $(\mathrm{mg})$ was 


\section{WILEY-VCH}

calculated using the $\mathrm{BV} / \mathrm{TV} \times \mathrm{BMD}$. After removing the titanium fiber and the conventional titanium plates along with the surrounding soft tissue and fixation in $20 \%$ neutral buffered formalin solution (Wako, Osaka, Japan), each specimen was embedded in Osteoresin (Osteoresin embedding kit, Wako, Osaka, Japan), sectioned using a saw microtome (SP1600, Leica AG, Glattbrugg, Switzerland), stained with hematoxylin (Muto Pure Chemicals, Tokyo, Japan) and eosin (Wako, Osaka, Japan), and the sections were examined under a light microscope (BX50, Olympus, Tokyo, Japan).

Inducing rat bone marrow mesenchymal cell differentiation into osteoblasts and evaluating skull bone defect repair in rats: The femurs of male Wistar rats (10 weeks of age; SLC, Shizuoka, Japan) anesthetized by isoflurane inhalation and administration of pentobarbital intraperitoneally (Nembutal, Sumitomo Dainippon Pharma, Osaka, Japan) were resected. After cutting off both ends of the femur, the marrow cavity was punctured using a $21 \mathrm{G}$ needle and $10 \mathrm{~mL}$ of $\alpha$-MEM medium containing 10\% FBS and Antibiotic Antimycotic (10,000 units/mL of penicillin, $10,000 \mu \mathrm{g} / \mathrm{mL}$ of streptomycin, and $25 \mu \mathrm{g} / \mathrm{mL}$ of amphotericin [15240062, Life Technologies, Grand Island, NY, USA]) was forced through the marrow cavity to remove the bone marrow, which was collected in a $10 \mathrm{~cm}$ dish. The bone marrow mesenchymal stem cells were cultured in $\alpha$-MEM medium containing $10 \%$ FBS in $10-\mathrm{cm}$ dishes, washed with Dulbecco's phosphate-buffered saline (D-PBS) (Nacalai Tesque, Kyoto, Japan) before replacement with fresh medium every 3 days, and allowed to proliferate to a density of approximately $2.0 \times 10^{6}$ cells/dish in 7 days ${ }^{[58]}$. On Day 10 , the cells were passaged, and half of the cells were cultured in a medium supplemented with rhBMP-2 (HZ-1129, Humanzyme, Chicago, USA) at a concentration of $100 \mathrm{ng} / \mathrm{mL}$ to induce differentiation into osteoblasts. Cells induced to undergo differentiation and cells not induced were cultured for 7 days, and lysed with $0.1 \%$ Triton X-100 (200 $\mu \mathrm{L} /$ well; Amersham Biosciences, Uppsala, Sweden). The recovered lysate solution was analyzed to determine its ALP concentration and protein concentration. ALP concentration $(\mathrm{mmol} / \mathrm{L})$ was determined with LabAssay ${ }^{\mathrm{TM}}$ ALP 


\section{WILEY-VCH}

(Wako, Osaka, Japan), which utilizes absorbance at a wavelength of $405 \mathrm{~nm}$ and a microplate reader (VERSA Max, Molecular Devices, Sunnyvale, CA, USA). Protein concentrations $(\mathrm{mg} / \mathrm{mL})$ were determined with the Protein Assay Bicinchoninate kit (Nacalai Tesque, Kyoto, Japan), which utilizes absorbance at $562 \mathrm{~nm}$. ALP activity was calculated as ALP content $(\mathrm{mmol} / \mathrm{L}) /$ protein concentration $(\mathrm{mg} / \mathrm{mL}) / 1000(\mathrm{~mol} / \mathrm{g})$ for each group $(\mathrm{n}=3)$. Osteoblasts differentiated from bone marrow mesenchymal stem cells according to the above-described method were seeded onto disc-shaped titanium fiber plates or conventional titanium plates at an initial concentration of $1.0 \times 10^{5}$ cells/plate, allowed to adhere to the plates overnight, and then used in experiments. After anesthetization of male Wistar rats at 10 weeks of age by isoflurane inhalation and pentobarbital $50 \mathrm{mg} / \mathrm{kg}$ subcutaneous injection, a $5 \mathrm{~mm}$ defect was created at the center of the skull using a trephine bur (Micro Tech, Tokyo, Japan). Each osteoblast-coated titanium fiber plate and conventional titanium plate was aseptically inserted into the skull defect of 5 animals. A $0.9 \mathrm{~mm}$ hole was made at the center of the conventional titanium plate before drilling two $1.5 \mathrm{~mm}$ holes into the bone cortex around the skull bone defect, and the plate was immobilized by suturing. In both groups, the plate was covered with the periosteum and sutured, and stable fixation of the implant at all skull defects was confirmed. Eight weeks later, the rats were sacrificed, and the skulls were removed and the specimen including the surgical site and its surrounding soft tissue, was resected from each skull. After fixation in $20 \%$ neutral buffered formalin solution, each specimen was embedded in resin using the Osteoresin embedding kit (Wako, Osaka, Japan), and cut into sections using a saw microtome. After HE staining, each section was examined under a light microscope. The percentage contact between the titanium fiber plate or conventional titanium plate and the regenerated bone tissue, defined as "length of contact between the regenerated bone tissue and the plate/full length of the plate," was measured on the sagittal surface at the center of the skull. 


\section{WILEY-VCH}

Statistical analysis: Data are expressed as the mean and standard deviation. Data were statistically analyzed by the Student $t$-test using the software program SPSS package R, version 3.0.1 (R Development Core Team, http://www.r-project.org). A P value of less than 0.05 was considered to indicate a significant difference.

Ethics: All animal experiments were performed after receiving approval by the ethics committee of Shinshu University in accordance with the Shinshu University Animal Use and Care Rules. 


\section{WILEY-VCH}

\section{Supporting Information}

Supporting Information is available from the Wiley Online Library or from the author.

\section{Acknowledgements}

We would like to thank the staff of the Division of Instrumental Research at Shinshu University. This work was supported by JSPS KAKENHI Grant Number 15K1554700.

Received: ((will be filled in by the editorial staff))

Revised: ((will be filled in by the editorial staff))

Published online: ((will be filled in by the editorial staff)) 


\section{WILEY-VCH}

\section{References}

[1] J. Van der Stok, E. M. Van Lieshout, Y. El-Massoudi, G. H. Van Kralingen, P. Patka. Acta Biomater. 2011, 7, 739.

[2] X. Liu, P. K. Chu, C. Ding. Mater. Sci. Eng. R 2004, 47, 49.

[3] B. Sivakumar, S. Kumar, T. S. N. Sankara Narayanan Wear 2011, 270, 317.

[4] M. Geetha, A. K. Singh, R. Asokamani, A. K. Gogia. Prog. Mater. Sci. 2009, 54, 397.

[5] B. Zanotti, N. Zingaretti, A. Verlicchi, M. Robiony, A. Alfieri, P. C. Parodi. J. Craniofac. Surg. 2016, 27, 2061.

[6] B. Guillaume. Morphologie 2016, 100, 189.

[7] N. Sumitomo, K. Noritake, T. Hattori, K. Morikawa, S. Niwa, K. Sato, M. Niinomi. J. Mater. Sci. Mater. Med. 2008, 19, 1581.

[8] M. Niinomi, M. Nakai, J. Hieda. Acta Biomater. 2012, 8, 3888.

[9] M. Niinomi, Y. Liu, M. Nakai, H. Liu, H. Li. Regen. Biomater. 2016, 3, 173.

[10] M Little, R. J. Langfordm, A. Bhanji, D. Farr. J. Craniomaxillofac. Surg. 2015, 43, 1705.

[11] P Henle, K. Ortlieb, K. Kuminack, C. A. Mueller, N. P. Suedkamp. Arch. Orthop. Traum. Sur. 2011, 131, 85 .

[12] C. H. Chen, R. K. Zhou. Zhongguo Gu Shang 2013, 26, 131.

[13] A. Kara, H. Celik, Y. Oc, M. Uzun, M. Erdil, C. Tetik. Acta. Orthop. Traumatol. Turc. 2016, 50, 665 .

[14] Y. M. Yan, W. P. Zhang, Y. Liao, Z. F. Weng, W. J. Ren, J. Lin, X. A. Tang. Zhongguo Gu Shang 2011, 24, 199.

[15] Zioupos P, Currey JD. Changes in the stiffness, strength, and toughness of human cortical bone with age, Bone, Volume 22, Issue 1, January 1998, Pages 57-66

[16] K.L.Wapner, Implications of metallic corrosion in total knee arthroplasty, ClinOrthopRelat Res, 271 (1991), pp. 12-20. 


\section{WILEY-VCH}

[17] Liebschner, M. A. K. Biomechanical considerations of animal models used in tissue engineering of bone. Biomaterials 25, 1697-1714(2004)]

[18] M. J. Beltran, C. A. Collinge, M. J. Gardner. J. Am. Acad. Orthop. Surg. 2016, 24, 711.

[19] C. Druschel, T. Pirvu, K. D. Schaser, P. Schwabe, I. Melcher. Unfallchirurg 2013, 116, 854.

[20] T. Zhang, Y. Guo, N. Hu, L. Chen, Y. Wu, Y. Wang, L. Liu, C. Zhao. Orthopedics 2016, 39, e1140.

[21] P. Kamiński, J. Szmyd, J. Ambroży, W. Jurek, J. M. Jaworski. Ortop. Traumatol. Rehabil. 2016, 18, 461.

[22] M. J. Long, H. J. Rack. Biomaterials 1998, 19, 1621.

[23] E. M. Younger, M. W. Chapman. J. Orthop. Trauma. 1989, 3, 192.

[24] C. J. Damien, J. R. Parsons. J. Appl. Biomater. 1991, 2, 187.

[25] S. G. Pneumaticos, G. K. Triantafyllopoulos, E. K. Basdra, A. G. Papavassiliou. J. Cell. Mol. Med. 2010, 14, 2561.

[26] M. Kalab, J. Karkoska, M. Kaminek, P. Santavy. Rozhl. Chir. 2016, 95, 399.

[27] P. V. Giannoudis, T. A. Einhorn, D. Marsh. Injury 2007, 38 Suppl 4, 3.

[28] J. W. Vehof, P. H. Spauwen, J. A. Jansen. Biomaterials 2000, 21, 2003.

[29] N. Kishimoto, Y. Momota, Y. Hashimoto, K. Ando, T. Omasa, J. Kotani. Cytotechnology 2013, 65, 15 .

[30] M. Hirota, T. Hayakawa, A. Ametani, Y. Kuboki, M. Sato, I. Tohnai. Int. J. Oral Max. Impl. 2011, 26, 245.

[31] X. He, Y. Liu, X. Yuan, L. Lu. PLoS One 2014, 9, e104061.

[32] Usui Y, Aoki K, Narita N, Murakami N, Nakamura I, Nakamura K, Ishigaki N, Yamazaki H, Horiuchi H, Kato H, Taruta S, Kim YA, Endo M, Saito N. Carbon nanotubes with high bone-tissue compatibility and bone-formation acceleration effect. Small 4(2): 240-246, 2008. 


\section{WILEY-VCH}

[33] M. Cicciù, A. S. Herford, E. Stoffella, G. Cervino, D. Cicciù. Open Dent. J. 2012, 6, 51.

[34] J. van den Dolder, P. H. Spauwen, J. A. Jansen. Tissue Eng. 2003, 9, 315.

[35] J. van den Dolder, E. Farber, P. H. Spauwen, J. A. Jansen. Biomaterials 2003, 24, 1745.

[36] N. Nakayama, M. Tamai, H. Horita, H. Miki, H. Utsumi, H. Takeishi. Journal of JSEM 2014, 14, 226.

[37] Korabi R, Shemtov-Yona K, Rittel D. On stress/strain shielding and the material stiffness paradigm for dental implants.Clin Implant Dent Relat Res. 2017 Jun 13.

[38] Saravana Kumar G, George SP. Optimization of custom cementless stem using finite element analysis and elastic modulus distribution for reducing stress-shielding effect. Proc Inst Mech Eng H. 2017 Feb;231(2):149-159.

[39] Itala AI, Ylanen HO, Ekholm C, Karlsson KH, Aro HT. Pore diameter of more than 100 microm is not requisite for bone ingrowth in rabbits. $\mathrm{J}$ Biomed Mater Res.2001;58(6):679-83.

[40] Kroese-Deutman HC, Vehof JW, Spauwen PH, Stoelinga PJ, Jansen JA. Int. J. Oral. Maxillofac. Surg. 2008, 37, 542.

[41] Lakhani RS, Shibuya TY, Mathog RH, Marks SC, Burgio DL, Yoo GH. Titanium mesh repair of the severely comminuted frontal sinus fracture. Arch Otolaryngol Head Neck Surg. 2001 Jun;127(6):665-9.]

[42] Nune KC, Misra RD, Li SJ, Hao YL, Yang R. Osteoblast cellular activity on low elastic modulus Ti-24Nb-4Zr-8Sn alloy. Dent Mater. 2017 Feb;33(2):152-165.

[43] Nune KC, Misra RD, Li SJ, Hao YL, Yang R. Cellular response of osteoblasts to low modulus Ti-24Nb-4Zr-8Sn alloy mesh structure. J Biomed Mater Res A.2017 Mar; 105(3):859-870.

[44] Guo S, Meng Q, Zhao X, Wei Q, Xu H. Design and fabrication of a metastable $\beta$-type titanium alloy with ultralow elastic modulus and high strength. Sci Rep.2015 Oct $5 ; 5: 14688$. 


\section{WILEY-VCH}

[45] A. Cipitria, C. Lange, H. Schell, W. Wagermaier, J. C. Reichert, D. W. Hutmacher, P. Fratzl, G. N. Duda. J. Bone Miner. Res. 2012, 27, 1275.

[46] D. P. Byrne, D. Lacroix, J. A. Planell, D. J. Kelly, P. J. Prendergast. Biomaterials 2007, 28,5544 .

[47] G. Han, W. E. Müller, X. Wang, L. Lilja, Z. Shen. Mater. Sci. Eng. C Mater. Biol. Appl. 2015, 47, 376 .

[48] C. M. Curtin, K. C. Chung. Ann. Plast. Surg. 2002, 49, 580.

[49] P. Hernigou, J. Pariat. Int. Orthop. 2017, 30, 1489.

[50] G. Buijze, P. Kloen. J. Bone Joint. Surg. Am. 2009, 91, 2416.

[51] F. Martetschlaeger, S. Siebenlist, G. Sandmann, T. Kraus, U. Stoeckle, M. Lucke. Eur. J. Trauma Emerg. Surg. 2010, 36, 537.

[52] R. Arora et al., Complications following internal fixation of unstable distal radius fracture with a palmar locking-plate. J. Orthop. Trauma. 2007, 21, 316.

[53] [FDA, Concerns about Metal-on-Metal Hip Implants. https://www.fda.gov/MedicalDevices/ProductsandMedicalProcedures/ImplantsandProst hetics/MetalonMetalHipImplants/ucm241604.htm]

[54] H. Schliephake, F. W. Neukam, D. Klosa. Int. J. Oral Maxillofac. Surg. 1991, 20, 53.

[55] A. Aarvold, J. O. Smith, E. R. Tayton, S. A. Lanham, J. B. Chaudhuri, I. G. Turner, R. O. C. Oreffo. J. Biomed. Mater. Res. A 2013, 101, 3431.

[56] S. F. Hulbert, F. A. Young, R. S. Mathews, J. J. Klawitter, C. D. Talbert, F. H. Stelling. J. Biomed. Mater. Res. 1970, 4, 433.

[57] M. M. D. Abràmoff, I. Hospitals, P. J. Magalhães. Biophotonics Int. 2004, 11, 36.

[58] H. Ohgushi, Y. Dohi, T. Katuda, S. Tamai, S. Tabata, Y. Suwa. J. Biomed. Mater. Res. 1996, 32, 333. 


\section{WILEY-VCH}

A

$1 \mathrm{~mm}$
B

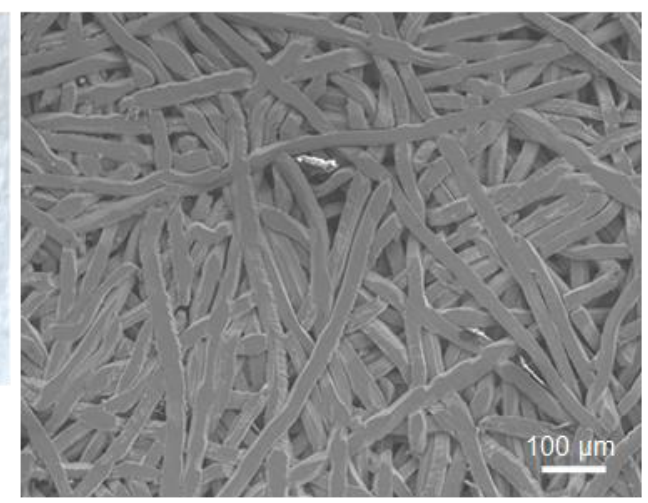

Figure 1 
WILEY-VCH

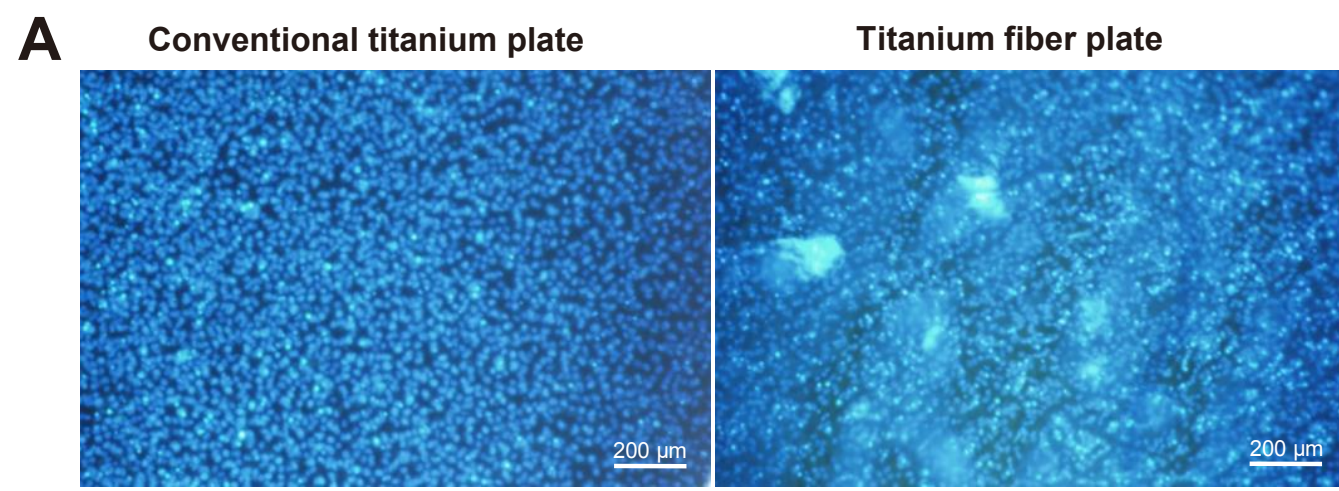

B

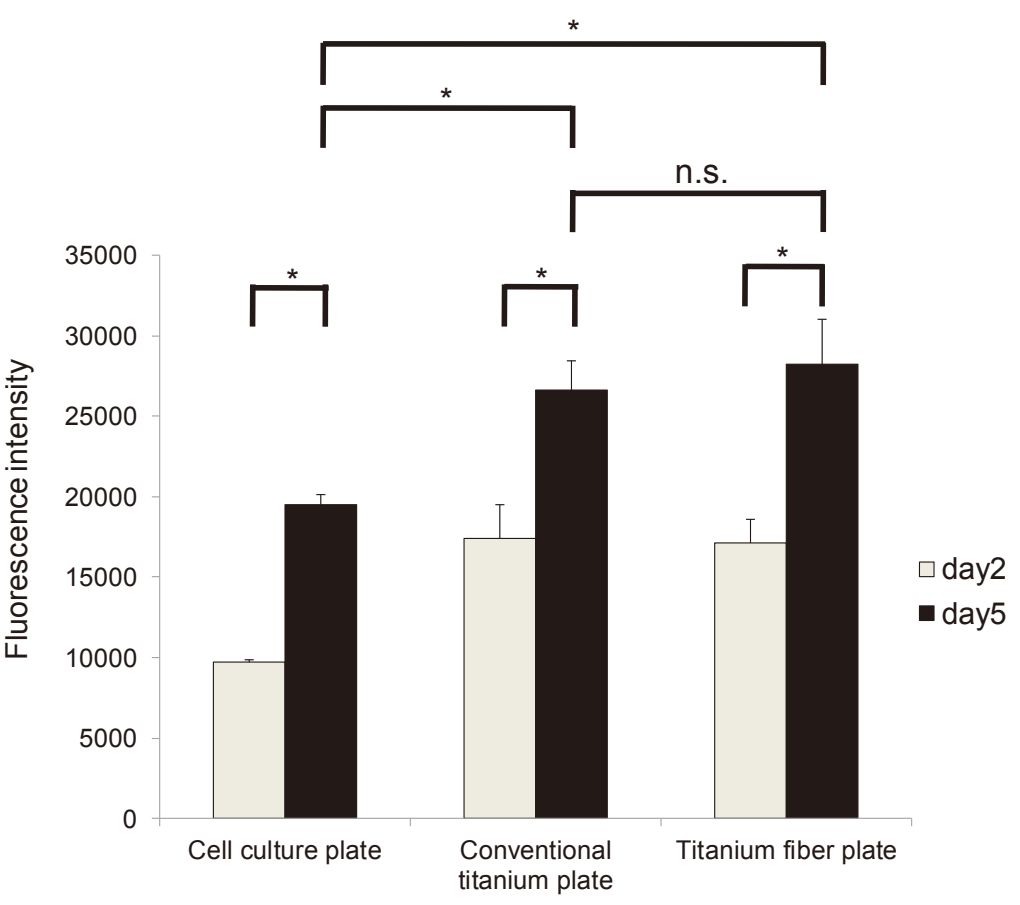

Figure 2 


\section{WILEY-VCH}

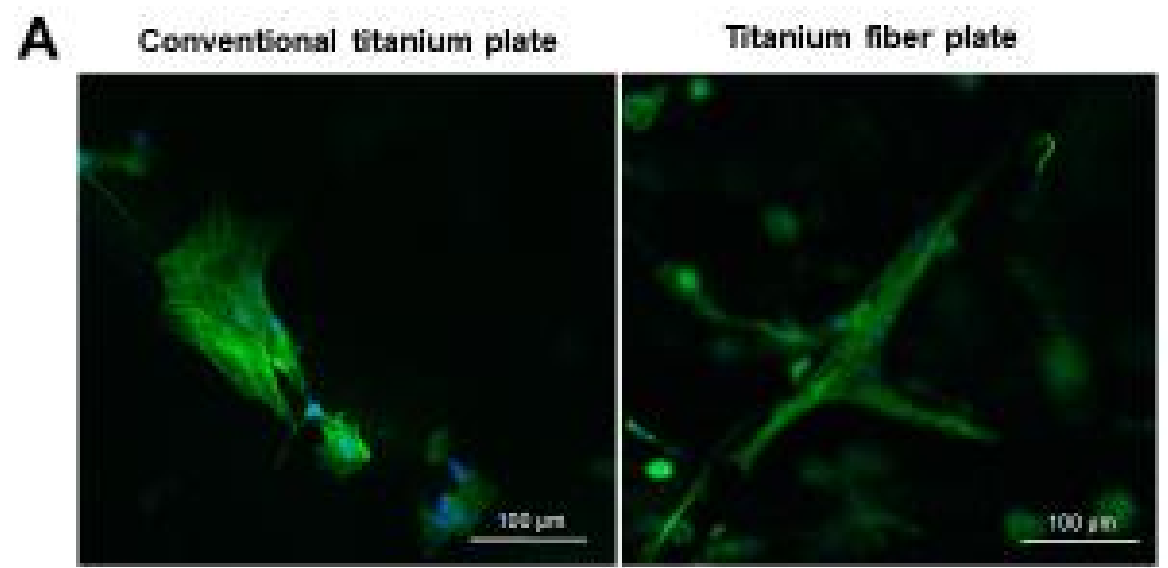

B Conventional titanium plate

Titanium fiber plate
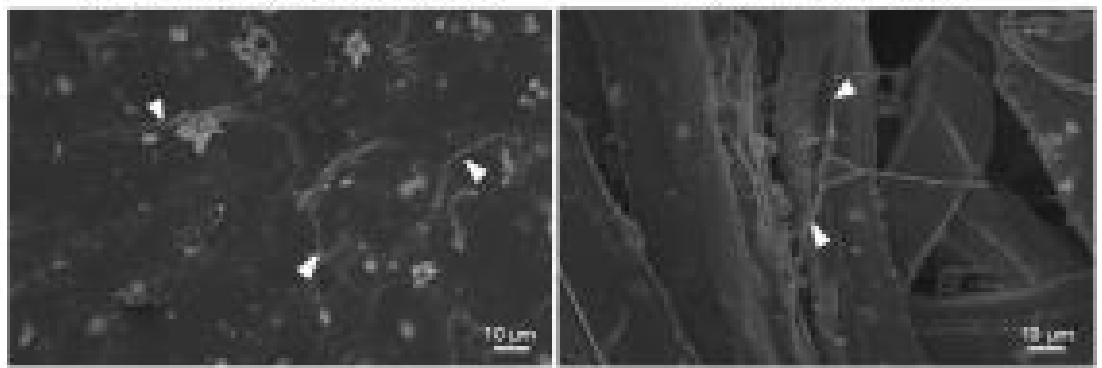

C

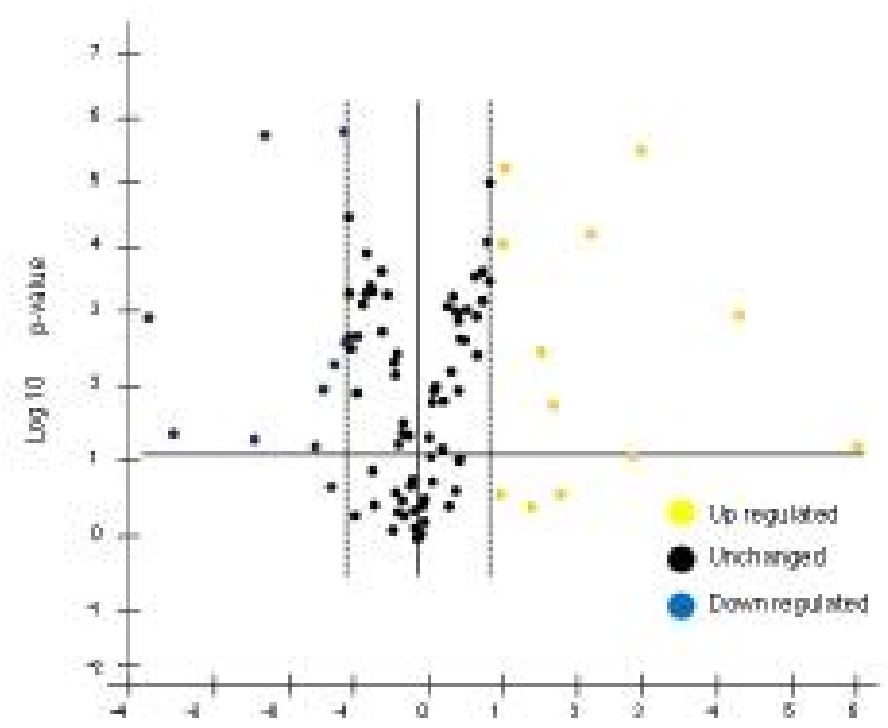

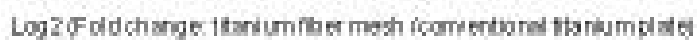

Figure 3 


\section{WILEY-VCH}
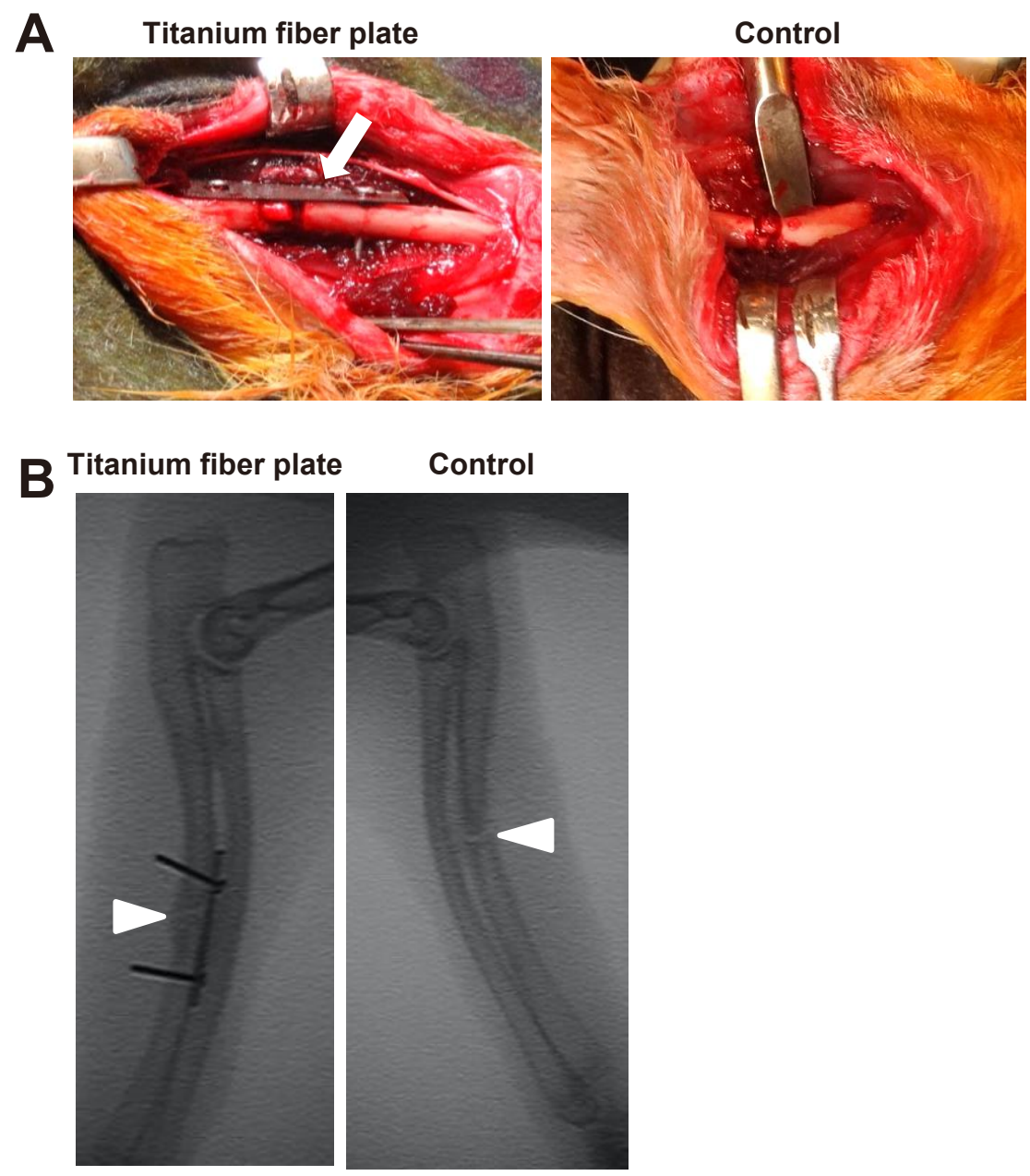

C Titanium fiber plate

Control

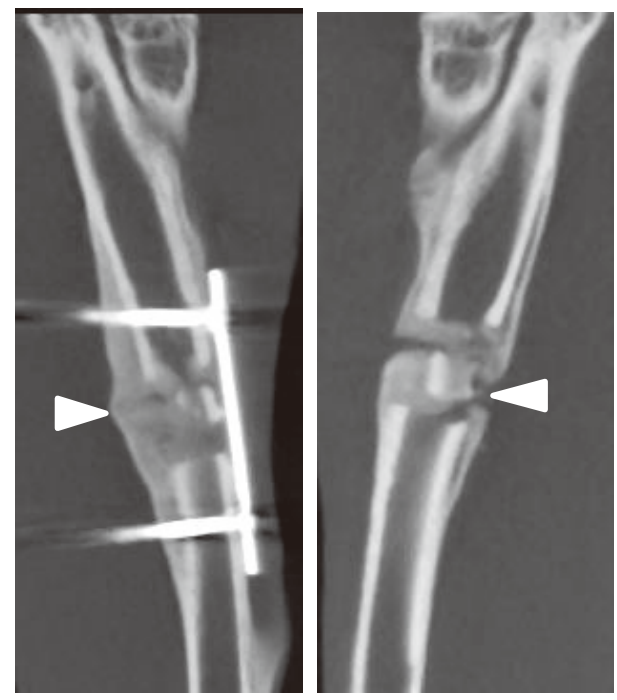

Figure 4 


\section{WILEY-VCH}

A Conventional titanium plate

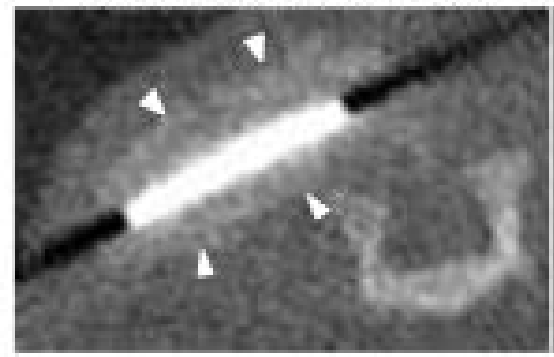

Titanium fiber plate
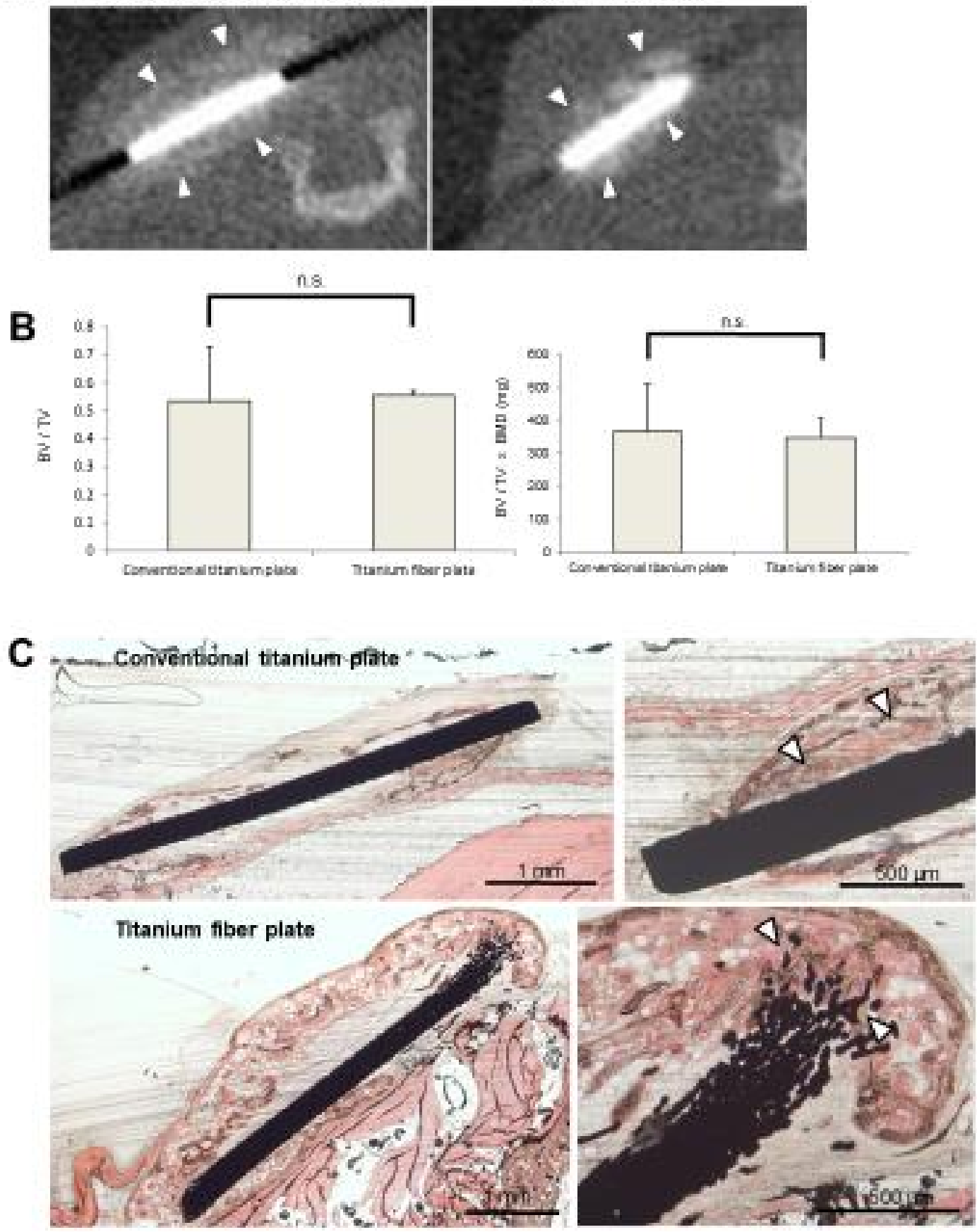

Figure 5 
A

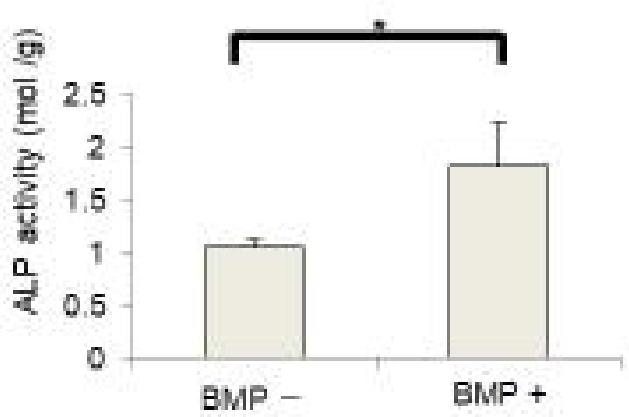

B

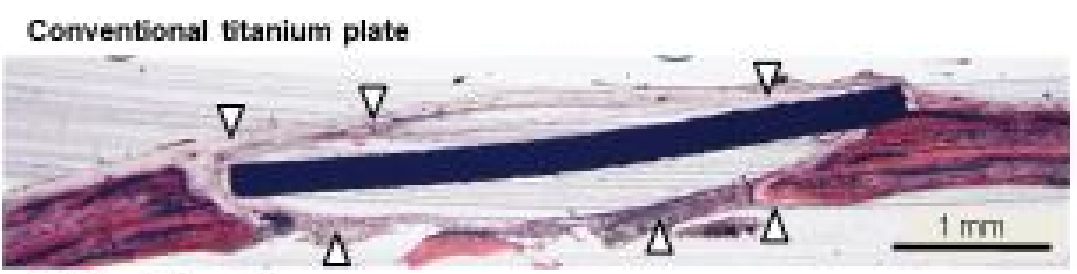

Thtanium fiber plate

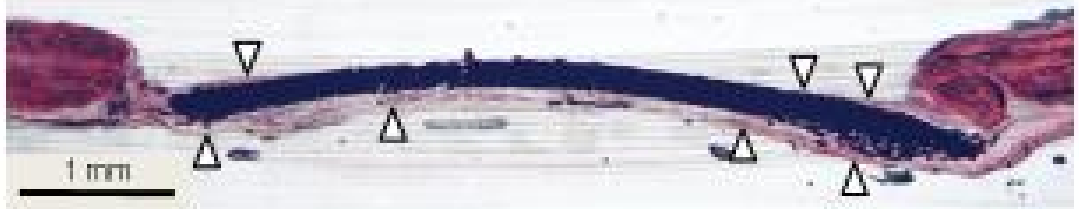

C

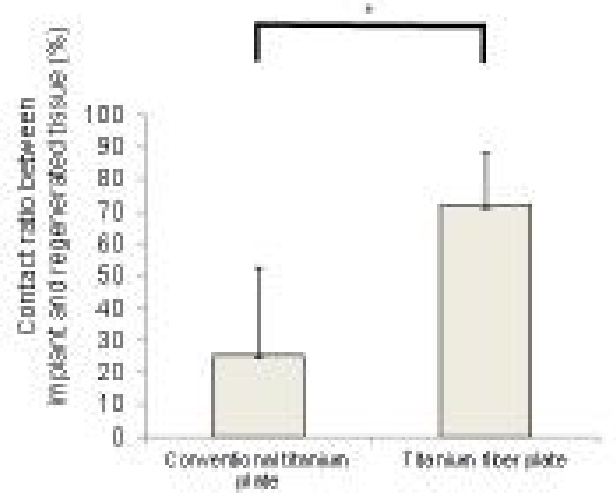

Figure 6 


\section{WILEY-VCH}

\section{Figure captions}

Figure 1. Images of a titanium fiber plate. (a) A macroscopic image. (b) scanning electron microscopic (SEM) image. A porous structure comprising compressed titanium fibers can be observed.MWCNT block.

Figure 2. Cultivation of MC3T3-E1 cells on a titanium fiber plate and a conventional titanium plate. (a) A fluorescence microscopic image of the cell nucleus stained with Bisbenzimide H33342 Fluorochrome Trihydrochloride. In both the titanium fiber plate and the conventional titanium plate, good cell adhesion was observed up to the periphery. (b) Cell proliferation capacity evaluated using the Alamar blue assay. Five days later, the extent of cell proliferation was similar between the titanium fiber plate and the conventional titanium plate. The extent of cell proliferation was statistically significantly greater on both titanium plates than on the cell culture plate. The error bars represent standard deviation. n.s.: Not significant. Asterisk: $\mathrm{p}<0.01$.

Figure 3. Morphology of adhering osteoblasts (induced by rhBMP-2 to differentiate from rat bone marrow mesenchymal cells) and cell adhesion gene expression. (a) Confocal laser microscopic image. Mesenchymal stem cells that had differentiated into osteoblasts on the titanium fiber plate can be seen to adhere to titanium fibers (arrows) by Bisbenzimide H33342 Fluorochrome Trihydrochloride (blue) staining of the cell nucleus and phalloidin-FITC (green) staining of actin fibers. (b) SEM image. Osteoblasts adhered to the titanium fiber plate as the titanium fibers were wound around the cell process (arrowhead). c, Expression level ratios for cell-adhesion-related genes in cells collected after induction of differentiation into osteoblasts. Gene expression levels were compared between the two groups by plotting the expression of each gene to visualize the changes in gene expression. The vertical solid line indicates the genes that were expressed on the titanium fiber plates and showed no significant 


\section{WILEY-VCH}

changes compared with the conventional titanium plates. The vertical dotted line indicates the expression changes by the 2-fold volume; the genes shown between the left and right lines exhibited expression level changes within the 2-fold volume. Yellow dots represent titanium fiber plate genes expressed at levels of $\leq 2$-fold compared with conventional titanium plates, and blue dots represent titanium fiber plate genes expressed at levels of $<2$-fold compared with conventional titanium plates. The horizontal solid line indicates statistical significance, with genes showing $\mathrm{p}<0.05$ plotted above this line. Of the 84 genes examined, 8 were expressed at statistically significantly higher levels in cells attached to the titanium fiber plate and 9 were expressed at statistically significantly higher levels in cells attached to the conventional titanium plate (calculated from the means for $n=3$ samples).

Figure 4. Repair of comminuted fractures using the titanium fiber plate in rabbits. (a) A $3 \times 3 \times 3 \mathrm{~mm}$ comminuted fracture was created at the center of the ulnar stem, and a titanium fiber plate was fixed to the ulna using miniature screws. Nothing was fixed in the control group. Outlined arrow: Titanium fiber plate. (b) Scout radiograms taken from rabbits in the titanium fiber plate group and control group at Week 4 postoperatively. Complete bone union was noted in the titanium fiber plate group but not the control group. Outlined arrowhead: area of fracture. (c) $\mu \mathrm{CT}$ images taken of the fracture site in the titanium fiber plate group and control group at Week 4 postoperatively. Circumferential bone repair was adequate in the titanium fiber plate group, but inadequate in the control group. Solid arrowhead: area of fracture.

Figure 5. Ectopic bone formation on the titanium fiber plate after coating with rhBMP-2 in mice. (a) $\mu \mathrm{CT}$ images of the titanium fiber plate or conventional titanium plate coated with 5 $\mu \mathrm{g}$ of rhBMP-2, taken 3 weeks after implantation into back muscle. Distinct ectopic bone formation was observed in both the titanium fiber plate group and the conventional titanium 


\section{WILEY-VCH}

plate group. Solid arrowhead: Ectopic bone formed. (b) Ectopic bone volume and total bone mass. For both indicators, no significant difference was found between the titanium fiber plate group and the conventional titanium plate group $(n=4)$. The error bars represent standard deviation. n.s.: Not significant. (c) Histologic image of ectopic bone formed around the plate. In the titanium fiber plate, bone tissue had entered the space between titanium fibers. Outlined arrowhead: Ectopic bone formed.

Figure 6. Bone regeneration in rat skull bone defects covered by the titanium fiber plate and osteoblasts. (a) ALP activity measured after culturing bone marrow mesenchymal stem cells from rat femur in rhBMP-2 (100 ng/mL)-containing culture broth or rhBMP-2-free culture broth. In the rhBMP-2-containing medium, ALP activity increased statistically significantly and the cells differentiated into osteoblasts $(n=3)$. The error bars represent standard deviation. Asterisk: $\mathrm{p}<0.01$. (b) Histological image taken at Week 8 after implantation in a rat skull bone defect. In the titanium fiber plate group, bone tissue formed around the plate, and bone regeneration was good. In the conventional titanium plate group, bone tissue formed only on a part of the plate and bone regeneration was inadequate. Arrowhead: Regenerated bone. (c) The percentage contact between the titanium fiber plate or conventional titanium plate and the regenerated bone tissue(defined as length of contact between the regenerated bone tissue and the plate/full length of the plate). The contact ratio was approximately 2.8 times, statistically significantly higher, in the titanium fiber plate group than in the conventional titanium plate group $(n=5)$. The error bars represent standard deviation. Asterisk: $\mathrm{p}<0.01$. 


\section{WILEY-VCH}

Table 1. Young's moduli of the family of titanium alloys and human cortical bone ${ }^{[4,15-16]}$

\begin{tabular}{|l|r|}
\hline Pure titanium/Titanium alloy/Cortical bone & Young's Modulus (GPa) \\
\hline Pure Ti $(\mathrm{Cp}$ grade $1-4)(\alpha)$ & 100 \\
\hline Ti-6Al-4V $(\alpha+\beta)$ & $110-112$ \\
\hline Ti-13Nb-13Zr (Metastabe $\beta)$ & $79-84$ \\
\hline Ti-12Mo-6Zr-2Fe (TMZF) $(\beta)$ & $74-85$ \\
\hline Ti-35Nb-7Zr-5Ta (TNZT) $(\beta)$ & 65 \\
\hline Ti-29Nb-13Ta-4.6Zr $(\beta)$ & 66 \\
\hline Ti-35Nb-5Ta-7Zr-0.40 (TNZTO) $(\beta)$ & $10-30$ \\
\hline Cortical bone & \\
\hline
\end{tabular}




\section{WILEY-VCH}

Table 2. Genes expressed at statistically significantly higher levels in cells attached to the titanium fiber plate than in cells attached to the conventional titanium plate after induction of rat bone marrow mesenchymal cell differentiation into osteoblasts.

\begin{tabular}{|l|l|l|}
\hline Gene & Expression ratio (x) & P-value \\
\hline Dsp & 69.69 & 0.039 \\
\hline Dsc3 & 22.23 & 0.0004 \\
\hline Ppap2b & 8.65 & 0.000002 \\
\hline Dsc2 & 5.31 & 0.00003 \\
\hline Pvr13 & 3.69 & 0.0096 \\
\hline Pkp1 & 3.27 & 0.002 \\
\hline Pvr11 & 2.30 & 0.000003 \\
\hline Clip1 & 2.27 & 0.00004 \\
\hline
\end{tabular}




\section{WILEY-VCH}

Table 3. Genes expressed at statistically significantly higher levels in cells attached to the conventional titanium plate than in cells attached to the titanium fiber plate after induction of rat bone marrow mesenchymal cell differentiation into osteoblasts.

\begin{tabular}{|l|l|l|}
\hline Gene & Expression ratio (x) & P-value \\
\hline Cdh5 & -13.6 & 0.0005 \\
\hline Dlg5 & -10.6 & 0.026 \\
\hline Pik3cg & -4.9 & 0.031 \\
\hline Lmo7 & -4.4 & 0.000001 \\
\hline Dsc1 & -2.7 & 0.039 \\
\hline Natch3 & -2.5 & 0.0056 \\
\hline Exoc2 & -2.3 & 0.0024 \\
\hline Was & -2.1 & 0.000001 \\
\hline Natch1 & -2.0 & 0.0017 \\
\hline
\end{tabular}




\section{WILEY-VCH}

Titanium fiber plates for bone tissue repair

Takashi Takizawa, Noboru Nakayama, Hisao Haniu, Kaoru Aoki, Masanori Okamoto, Hiroki Nomura, Manabu Tanaka, Atsushi Sobajima, Kazushige Yoshida, Takayuki Kamanaka,

Kumiko Ajima, Ayumu Oishi, Chika Kuroda, Haruka Ishida, Satomi Okano, Hiroyuki Kato, and Naoto Saito

Supporting Information 


\section{WILEY-VCH}

\section{Methods}

\section{Preparation of titanium fiber plates}

In the present study, the material used for plate preparation was $99.52 \%$ pure (ASTM grade 1) fibrous titanium, with each fiber having a diameter of approximately $20 \mu \mathrm{m}$. Fibers with an aspect ratio $(\mathrm{AR}=$ diameter/height $)$ of 100 were prepared. Fig. S1 shows images of the titanium fibers. The side view of one fiber shows a surface asperity.

A schematic diagram of the COSME-RT process is shown in Fig. S2. First, pure titanium fibers are placed on a stationary plate. A moveable plate is then placed on top of the stationary one, and a compression stress $\sigma_{N}$ is then applied to the moveable plate and sustained during the formation process. A shearing load is also applied to the moveable plate, which is displaced in the shearing direction.

The thin titanium fiber plate was fabricated by repeating this procedure. Since there is a risk that the thin titanium fiber plate will be broken by high strain produced by sudden application of pressure, the formation process was performed repeatedly under low strain conditions. The number of repetitions is referred to as the shearing number $N$. Reprinted with permission from Ref. [36] . Copyright 2014 JSEM.

\section{Evaluation of porosity}

In order to investigate the porosity of specimens in more detail, mercury intrusion tests were performed. The mercury intrusion test depends on the large surface tension characteristics of mercury to determine the porosity and pore diameter of specimens from the cumulative volume of intruded mercury and the applied pressure. Reprinted with permission from Ref. [36]. Copyright 2014 JSEM. 


\section{WILEY-VCH}

\section{Figure legends}

Figure S1. SEM images of the starting material, titanium fibers. Reprinted with permission from Ref. [36]. Copyright 2014 JSEM.

Figure S2. Schematic diagram of the process used for preparing titanium fiber plates. Reprinted with permission from Ref. [36]. Copyright 2014 JSEM. 


\section{WILEY-VCH}

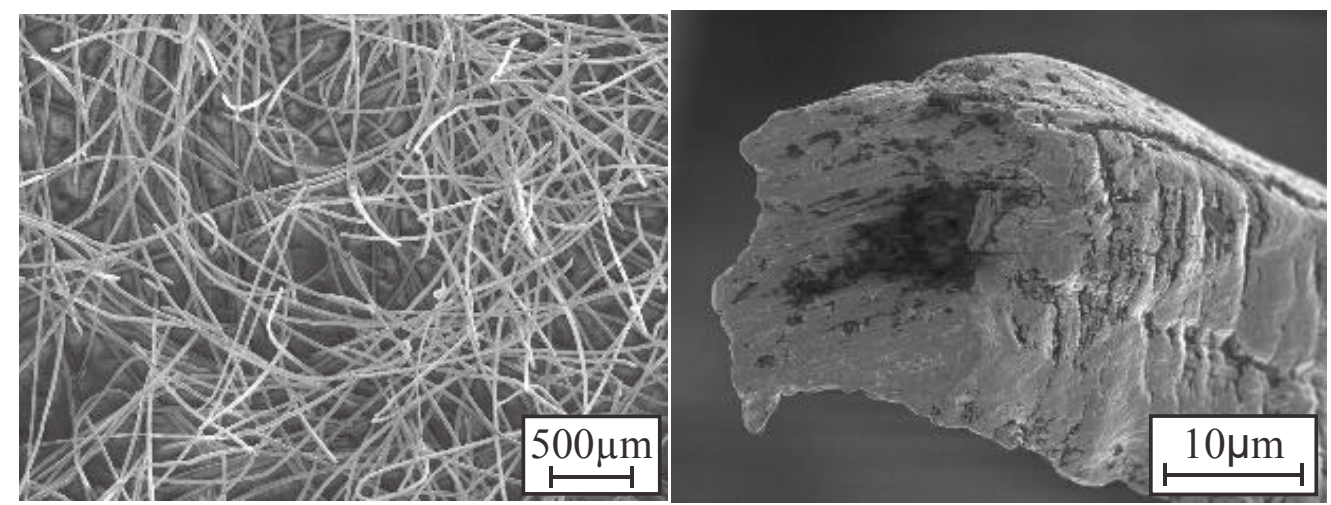

Figure S1

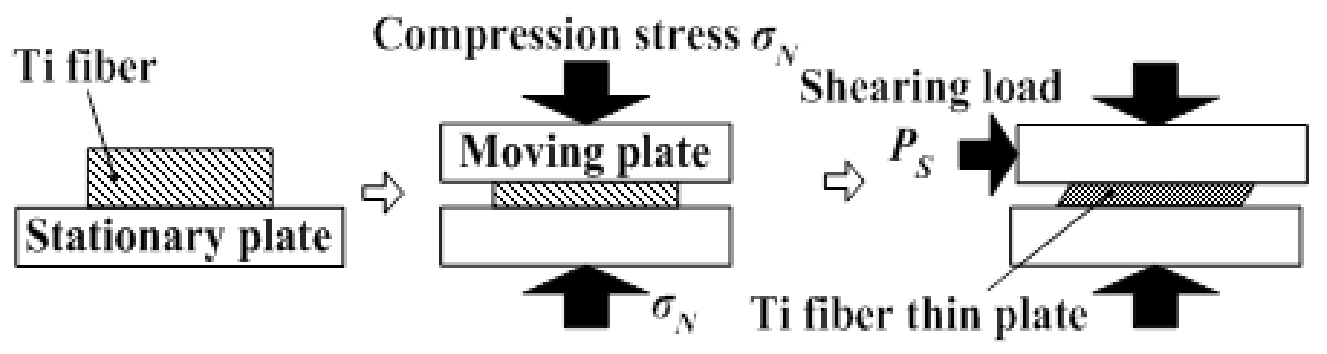

Figure S2 